\author{
Olexiy Stupnitsky \\ PhD (Economics), Professor \\ Department of International Business \\ Taras Shevchenko National University of Kyiv, Kyiv, Ukraine \\ E-mail: a.stupnitsky@ukr.net \\ ORCID: https://orcid.org/0000-0002-5508-5625 \\ Olena Pryiatelchuk \\ Doctor of Economics, Associate Professor \\ Department of International Business \\ Taras Shevchenko National University of Kyiv, Kyiv, Ukraine \\ E-mail: pryyatelchuk@gmail.com \\ ORCID: http://orcid.org/0000-0002-5222-452X
}

\title{
Intelligence technologies in logistic infrastructure modernisation
}

\begin{abstract}
The purpose of the paper is to determine the impact of innovative technologies of artificial intelligence on the modernization of logistics infrastructure, the formation of new forms of logistics networks of Industry 4.0. Methodology. The survey is based on a study of the main trends in the field of logistics infrastructure development, analysis of the latest forms and methods of using artificial intelligence technologies in various fields. The study considers the forecasts of IDC "IDC Future Scape: Worldwide Digital Transformation 2021" and contains an assessment of the volume and effectiveness of investment in this area. The results of the survey showed that in addition to the radical transformation of the logistics network itself, the use of artificial intelligence technologies will lead to qualitative changes in the labor market. There is still the tendency to reduce the need for logisticians performing operational functions automation of warehousing operations, unmanned stackers, and transporters instead of loaders and pickers will accelerate. Practical implications. The use of artificial intelligence technologies allows companies today to generate significant competitive advantages on this basis. However, soon this will not be an advantage, an indisputable condition for the company's operation in the market of logistics services in general. Value/originality. The authors have highlighted the minimum quality and competencies required in the future, the presence of which in the company's resource base will allow to use all the advantages of implementing innovative forms of piece intelligence - multi-competent knowledge in the areas of IT technologies, procurement and warehouse, transport, production and distribution logistics, mathematical analysis, and production management processes based on artificial intelligence.
\end{abstract}

\section{Keywords}

Logistics, innovations, intelligence, modernization, digitalization

JEL: F01, L91, O31

DOI: https://doi.org/10.30525/2500-946X/2021-1-3

\section{Introduction}

Modern large transport and logistics companies such as Acteos, Akanea, Infor, Manhattan Associates, OMP/GPI Xyric and Cofisift/Xyric are both software developers for AI technologies and consultants on their further use. And although the world's leading database operators (SAP, Microsoft Oracle, IBM, etc.) have integrated artificial intelligence (AI) into their commercial offerings, it is specialized logistics companies that develop, update, and improve AI-based software algorithms. This allows: automated decision-making when carrying out necessary operations; operating automatic stackers $(A G V)$ or warehouse drones; analyse the situation and determine the minimum number of employees required for the full operation of the warehouse; effectively use autonomous logistics robots that combine AI with stereoscopic cameras, create and store a map of the surrounding area, safely bypass employees, stationary obstacles and other handling equipment.
In early 2020, Stanford University (USA) released the results of a study according to which, for more than seven years, the computing power of AI has been ahead of Moore's Law, according to which the processor speed doubles every 18 months, which means that developers can expect a doubling of application performance during this time frame with the same equipment cost. These results, prepared by a consortium of companies McKinsey \& Company, Google, PwC, OpenAI, Genpact and AI21Labs, show that AI computing power is growing faster than traditional processors, and the tipping point (when the speed of AI development began to outstrip Moore's Law) was 2012.

In early 2021, the largest logistics operator and leader in the contract logistics market, DHL, released the fifth edition of the Logistics Trend Radar, a kind of seismograph for identifying future trends in the Supply Chain industry. It identifies 29 key trends that will affect it in the medium term and, in particular, states that "the COVID-19 pandemic has led to dynamic changes in the digital logistics of the 
workspace and has brought the digitalization of the industry closer by several years" (Eremina, 2019).

Modern system software with elements of artificial intelligence (AI) has penetrated almost any field, becoming widespread and high-demand due to growing volumes of data, increasing computing power of computers and intensifying performance of algorithms. The logistics infrastructure of Industry 4.0 is no exception - AI technology is used from the automotive industry to air transport and telecommunications. It reveals potential opportunities for logistics business development, attracts new investments and facilitates changes in existing business processes. According to Stanford University 'AI Index Report 2021' and IDC's IDC 'Future Scape: Worldwide Digital Transformation 2021', investment in AI technology grew 40\% in 2020, reaching 67.9 billion USD and its sales are expected to be approximately 106 billion USD by 2025 (8.1 billion USD in 2018) at an annual growth rate of $15.5 \%$ (CAGR). (Weiyu, Keng, 2019).

\section{AI technologies in logistics supply chains}

Digital logistics in Industry 4.0 currently includes: Artificial Intelligence (AI); Big Data; Machine learning; Internet of Things (IoT).

They are a new approach to the management of logistics infrastructure and Supply Chain 4.0 for the efficient distribution of materials, products, and services from enterprises to customers (B2C) and from enterprises to enterprises (B2B).

AI technologies in logistics supply chains. Digital logistics services require predictable and intelligently supported operations, introduction of AI technologies in the supply chain combined with traditional and digital logistics, and new models of interaction with customers. Today, in Supply Chain 4.0 logistics, real-life situations are actively simulated on the principles of AI, planning is integrated into a general system of autonomous resource potential management for solving both applied and global problems.

AI technologies are being used in logistics supply chains to solve the following problems, such as: calculation of the optimal route; risk assessment to determine the cost of cargo insurance; forecasting the optimal loading of transport; building differentiated logistics supply chains; visual control of safety at the warehouse; the use of unmanned vehicles and delivery robots. (Kotsenas, Balthazar, 2020).

The main data for AI technologies when analysing the efficiency of logistics operations are: location of production, distribution warehouses and points of sale; movement of warehouse stocks; quantity, delivery routes and technical characteristics of transport; sales volumes in retail outlets, schedules and volumes of deliveries from contractors, temporary "windows" for product delivery to stores; traffic situation, meteorological conditions, etc.

The networked nature of the logistics industry and the large volume of day-to-day data (accounting, finance, human resources, legal support, and information technology) used by companies provide a natural basis for realizing the power of $\mathrm{AI}$ to save time, reduce costs, and increase productivity while taking on routine operations. Currently, a large number of specialized companies offer users all kinds of software, computer equipment for its application, as well as modern AI technologies used for supply chain management and Big Data analysis in logistics (retail chains, maintenance of warehouse complexes and inventory management, development of autonomous transport funds). They include the following systems:

a) analysis of a large number of orders in online stores to determine the greatest consumer demand and forecast trade trends in the future;

b) integrated enterprise management information (enterprise resource planning, ERP);

c) warehouse management with address storage (WMS);

d) control of automated technical means and unmanned aerial vehicles;

e) Transport Management System (TMS) to determine the most efficient transport routes and analyse performance;

f) managing the cycle of the current state of the vehicle to proactively calculate maintenance times and minimize the risk of breakdowns.

The use of new AI technologies in supply chains is a way to maintain the competitiveness of the logistics business, the purpose of which is:

a) analysis of a large array of internal / external data of the logistics environment;

b) search and formulation of proposals for making decisions regarding process planning at the right time and in the right place;

c) creation of a system of 'smart alerts'.

\section{Using AI technologies to optimise supply chains}

To avoid critical supply chain disruptions, logistics companies use the $\mathrm{ABC}$ operating model:

A. A complete picture of the entire logistics ecosystem.

B. Accurate forecasting of supply and demand.

C. Optimal planning of logistics and delivery.

The implementation of the $A B C$ operating model in the logistics industry allows the use of AI technologies both inside the company (back office) and in the external environment (front office), which helps move from reactive actions to proactive operations with smart forecasting. Today, the operating model of the TNC supply chain consists of many links (suppliers of components and raw materials, manufacturers, logistics firms, distributors, warehouses, carriers, retail chains, etc.) and is a transnational network. All links of the Supply Chain exchange information, and the efficiency of the business of all participants in the supply chain depends on the speed of this exchange and the quality of the transmitted data. AI finds such interdependencies that the employee cannot build, because there is no direct connection between the data, and their volumes are huge (the criterion of predictability of logistics is determined by facts, and not by the subjective judgment of the individual). When planning the work of a logistics operator, weather and road conditions are entered into the software algorithm in real time to continuously optimise the calculation of the best transportation route.

At the same time, AI technologies allow:

- determine the required number of vehicles to fulfil orders received from customers, calculate transportation costs, revenues and profits;

- create comfortable driving conditions through identification of road signs and markings, response to weather and traffic situations;

- manage autonomous freight vehicles (through devices designed to monitor the condition and amortisation of 
components and assemblies in real time, depending on the state of the vehicle, and not on the mileage);

- process data from other vehicles and infrastructure facilities, taking into account the risks of breakdowns on the way and forecasting the timing of maintenance; - perform an automatic analysis of the fundamental documents of transport companies (registration certificates, extracts from the $K$-bis trade register, transport licenses, and social security certificates) and check their reliability by comparing them with the national database.

AI technologies enable logistics companies:

Firstly, to accurately alert about supply problems and, accordingly, take the necessary (preventive/corrective) steps in advance. For example, the largest French company Carrefour Group has been using the SAS Viya analytical platform based on AI technology since 2019 to build a more efficient supply chain. Its implementation ensures collection and processing of data received from stores (including online stores) and from warehouses, increases the accuracy of forecasting, reduces the risks of overstocking, shortage of inventory, write-off volumes of expired products, which ultimately allows you to build an effective multichannel distribution and optimization of warehouse stocks.

Secondly, to realise cost savings and improve business processes. For example, independent research firm Practica estimates that by the end of 2021, sales of warehouse and logistics robots with AI will reach 22.4 billion USD. United Parcel Service (UPS) saves about 10 million gallons of fuel annually thanks to Big Data analysis combined with AI.

Thirdly, to introduce smart contracts into supply chains with more efficient transactions in large networks with a huge number of stores in different regions and an enormous data flow.

\section{Conclusions}

AI-based expert systems have already proven their ability to improve the productivity and quality of logistics operations, transform data and information into useful knowledge, find and share rare experiences and skills, and manage knowledge as a vital resource for competitiveness. In fact, optimization of logistics is based on the decomposition principle - a large task is divided into many small ones, which are then linked together with the help of a special coordinating task.

In the future, the tendency to reduce the need for logisticians performing operational functions (suppliers, dispatchers, shipping specialists, warehouse managers, etc.) will accelerate - automated warehouse operations, unmanned stackers, and transporters instead of loaders and pickers. In the next 5-7 years, such a profession as a freight forwarder may become a rudiment due to the emergence of electronic Internet services that connect the cargo owner with agents, carriers, terminals, insurance companies and select delivery schemes. AI technologies will significantly affect the list of professions in logistics: such specialties as a cross-logistics operator, a BTS coordinator, a designer of intermodal transport hubs and smart roads, a transport network security engineer, an architect of intelligent control systems will be in demand. It is the latter that will have the highest value of multi-competent knowledge in the fields of IT technologies, procurement and warehouse, transport, production and distribution logistics, mathematical analysis and management of AI- based production processes.

Currently, the introduction of AI into the logistics industry is taking place in the following areas.

1. Effectiveness of data management and customer service. One of the main benefits of introducing AI into the logistics industry is the ability to provide better customer service (especially to consumers who use online ordering). Nowadays, with the growing number of e-commerce businesses, all logistics companies have cloud databases that provide instant access to customer and order data. The efficiency of managing the day-to-day activities of a logistics company is determined by availability, costs, transportation, staffing, suppliers and monitoring flows and resources in order to ensure the quality of customer service.

2. Improving labour safety for employees. Occupational safety is paramount to any business, regardless of its size or industry. In the logistics industry, it is no longer so much about minimising payments and compensation for injuries, but about legal and moral obligation of companies to provide their employees with a safe work space. This ultimately leads to increasing productivity, satisfaction and loyalty of employees, relieving employees of dangerous work procedures and enhancing work efficiency in general. For example, a packaging and palletising robot can eliminate any risk of injury while performing industrial tasks, which saves employees' time and relieves them of the stress caused by repetition.

3. Improving the accuracy of supply chain processing. With the help of AI, logistics companies can more effectively manage all processes in the supply chain with a proactive logistics system that not only contributes to faster delivery, but also provides the ability to determine if there is an increase (or decrease) in demand from their customers, and adjust the volume of production in order to reflect the trend. AI improves the process of managing and analysing massive amounts of data as spreadsheets and other abandonware are no longer effective in data management. Real-time tracking process based on proactive logistics results in fewer human errors, lost or misplaced orders.

4. Reducing costs. The introduction of AI and automation in the field of logistics has a huge impact on cost reduction, as it reduces the number of errors in decision-making by logistics operators. Thus, large loads containing hundreds of orders that are lost or mishandled require huge costs to locate them, change the route and correct the situation. Under these conditions, AI not only allows better data management (due to the accuracy of all processes), but also by automating it, reduces the need for the number of employees, which leads to cost savings.

\section{References}

[1] Eremina, L. V., Mamoiko, A. Yu., \& Papikyan, A. S. (2019). Improving the efficiency of logistics planning through the use of artificial intelligence. Technics. Technologies. Engineering, 4 (14), 1-7. E-source: https://moluch.ru/th/8/ archive/142/4404/

[2] Iphofen, R., \& Kritikos, M. (2018). Regulating artificial intelligence and robotics: ethics by design in a digital society. DOI: https://doi.org/10.1080/21582041.2018.1563803 
[3] How Analytics and AI are Changing the Future: 8 Trends for 2021. E-source: https://ai.cnews.ru/articles/2021-01-31_ kak_analitika_i_iskusstvennyj_intellekt

[4] Kotsenas, E., Balthazar, P. \& others (2020) Rethinking Patient Consent in the Era of Artificial Intelligence and Big Data. DOI: https://doi.org/10.1016/j.jacr.2020.09.022

[5] Revolutionizing: How the Cargo Industry Is Using the Internet of Things and Artificial Intelligence. E-source: http://vestnik-glonass.ru/news/tech/sovershaya-revolyutsiyu-kak-gruzovaya-otrasl-ispolzuet-internet-veshcheyi-iskusstvennyy-intellekt/

[6] Weiyu, W., \& Keng, S. (2019). Artificial Intelligence, Machine Learning, Automation, Robotics, Future of Work and Future of Humanity: A Review and Research Agenda. DOI: https://doi.org/10.4018/JDM.2019010104 